\title{
Standardization and the Democratic Design of Information and Communication Technology
}

\author{
Eric Iversen*, Theirry Vedel, Raymund Werle
}

\begin{abstract}
Eric J. Iversen is the Guest Editor of this issue of $K T \& P$. His biographical sketch accompanies his Introduction.

Raymund Werle is principal research associate with the Max-Planck-Institut für Gesellschaftsforschung (Max Planck Institute for the Study of Societies) in Cologne, Germany. His current research is focused on the interaction of technical and institutional innovations and on the evolution, development and governance of the Internet. He may be reached at<werle@mpi-fg-koeln.mpg.de>.

Thierry Vedel is a researcher with the National Center for Scientific Research (CNRS) in Paris. He is based at the Center for Political Resarch (CEVIPOF) at the National Fondation for Political Science. Having worked on public policies in the area of new communication technologies, he is currently engaged in research on electronic democracy and the governance of communication networks in a context of globalization. Thierry Vedel teaches Communication and politics at the University of Paris 2 and at the Institut d'Etudes Politiques de Paris. He may be reached via <http://www.cevipof.msh-paris.fr/.>
\end{abstract}

The way information and communication technology (ICT) develops can promote or hinder the democratic potential of this critical societal infrastructure. Concerns about the role standards development organizations (SDOs) play in this context predate the 'digital age' but are reemerging amid substantial changes in the institutional landscape of standardization. This article explores the increasingly critical link between the institutional design of SDOs and the democratic design of ICT. We review some principles of democracy in terms of the design of technology, apply these to standardization, and discuss the role public policy may play here, while distinguishing between input and output legitimacy. 
*This author acknowledges support from the Norwegian Research Council, SKIKT Program for his participation in this article. 


\section{Introduction}

In 1974, a US congressional subcommittee report emphasized the need to secure equitable access to voluntary technical standardization. ${ }^{i}$ This report warned of committee standardization's tendency to structurally exclude relevant interests from participating in the shaping of technical standards and that the internationalization of standards development organizations (SDOs) threatens to further remove this activity - which is particularly important to network technologies - from the reach of those who would be affected by decisions made here. Since these issues were raised in a public policy framework thirty years ago, voluntary standardization has increased many times in importance especially for the elaboration of information and communications technology (ICT), a multipurpose network technology. The ICT standardization regime has undergone a comprehensive phase of proliferation and internationalization in step with emerging (and merging) information and communication technologies. The landscape of SDOs is global and fragmented, and there is no indication that it develops towards a unitary system even though some observers would find it attractive to cut back the organizational plethora (cf. Genschel 1997).

In recent work the socio-economic importance of voluntary standardization has been emphasized. But at the same time concerns over the fragmentation of standardization, the governance of SDOs, access to them and other issues have become acute, while the role of public policy has become less clear (cf. Mattli (ed.) 2001). Repeatedly it is called for broader participation opportunities in the standardization process (Tarmarin 1988, Rankine 1995, Jakobs 2000, Egyedi 2001) which would also improve its democratic quality. In this article, we integrate these discussions into the frame of the larger discussion of 'democratic ICT' to address the question of how public policy can promote the democratic design of ICT. We look at standards development organizations collectively as an institution and ask how the governance of standardization can be used to improve the democratic design of ICT. The question of participation - and thus representation - is one of two central aspects of democratic design of ICT which we will explore. The other one involves ensuring ex-post that standards improve compatibility with democratic principles. The focus of the paper is therefore the intersection between the (democratic) design of ICT and the institutional design of standardization. It is based on the assumption that the institutional design of standardization impacts on the design and architecture of network technologies. The paper will:

1. Explore perspectives on the relationship between society and network technology and explicate what is meant by the 'democratic design' of network technologies.

2. Focus on the design of the changing regime for standardization as a locus for improving the integration of democratic principles to technological development.

3. And analyze how democratic design principles are integrated in the process of standardization.

\section{Principles of democracy and the design of technology}


It is not the first time the idea of democracy has been introduced into a discussion about the design and development of technology. Several times in the late 1970s and throughout the 1980s, the relationship between technology and democracy and the possibility of democratic control of technology were an issue with a focus on high risk technologies such as nuclear power plants. It was argued that these technologies have an inherent (structural) risk potential and that at the same time the potential damage caused by an accident or a hostile attack would require safety provisions which are detrimental to a democratic society. This more traditional focus has of course acquired new relevance after hijacked commercial airliners were used to attack the World Trade Center and the Pentagon.

The renaissance of this discussion, however, predates September 11, 2001. It focuses on information and communication technology in general and the Internet in particular, asking how these may be relevant to upholding or strengthening the mainly operative principles of democratic governance. Without going into the theoretical and conceptual deliberations of what the term democracy encompasses in detail, it does not appear to be contentious that the term includes a set of principles and rules which shape individual attitudes and beliefs and directly influence the way people think and act. But in democratic governance systems these democratic principles and rules are also integrated in negotiation and decision-making procedures. This procedural dimension is a distinctive feature of a governance system in which power is devolved to all members of the system. In general, a democratic governance system requires operating rules which match democratic values and produce democratic outcomes. Such principles and rules of democratic governance include (Vedel 1999, Catinat and Vedel 2000):

- Openness - all interested parties can participate or are represented in collective decision-making.

- Equality - all parties have the same rights.

- Access - the parties have access to the information they consider relevant and to the technical means necessary to collect and evaluate the information.

- Transparency - the relevant principles and rules must be clear and known by all interested parties.

- Accountability - procedures and rules must be available to identify the responsible actors without infringing upon somebody's privacy.

- Contestability - it must be possible to challenge opinions, decisions and actions without violating freedom of speech principles.

The principles and rules of democracy provide the criteria to evaluate the democratic quality of structures and procedures of organizations, socio-technical systems and nations . Over time, some of these principles and rules may change - facilitated and stimulated by the opportunities of communication and exchange in global networks such as the Internet. But usually these changes will affect specific norms rather than more abstract formal values and principles of the kind listed above (CSTB 2001, 74-169; see also Engel and Keller 2000).

While it would be an exaggeration to regard single technical artifacts as democratic or undemocratic, the case may be different with more encompassing technical systems and infrastructures. The design and architecture of a technical system can be more or less compatible with the values and principles of democracy ${ }^{\text {ii }}$. Unlike high risk technologies, ICT is a (systemic) network technology that engenders not only risk factors but also support factors for democracy 
(Barber 2002). The technology is shaped by society, but it also shapes the society and its political structure (Werle 2000). It may promote or hinder, but it does not determine democracy.

Recent technological developments have actualized and spurred the discussion about the democratic potential of ICT. Innovations involving networks and services have expanded the capabilities and reduced the cost to transmit voice and text, data and images across geography in real time. They have convincingly demonstrated the potential to reshape the organization of our society. In this light, the idea of an Information Society has especially served to invite a discussion of democratic principles into the realm of technology. One dimension of the metaphor of the Information Society is that it recognizes the underlying interrelationship between society and technology in which economic, social and cultural processes of change interact with technological changes. These changes are ambivalent and may lead to different kinds of information society, more or less democratic. To some degree the democratic quality depends on how ICT is applied. This again is contingent "on how public authorities are able to frame their usage" (Catinat and Vedel 2000, 84). But according to the view that "technologies are social in their origins as well as their effects" (Mackay 1995, 41-42), it is not only the usage frame but the frame within which the technology is designed that play a crucial role in shaping the democratic quality of technology. Compliance with democratic principles in the social processes of technology construction will likely be reflected in the structure of technology and its democratic potential to a certain degree.

The social and political significance of ICT is notable in several ways. The most important peculiarity involves the scope and breadth of large ICT systems, where information and communication infrastructures can be regarded as permeating society in a way that is analogous to a nervous system. The combination of the scope, the breadth, and the degree of permeation of such systems underlines the importance of their democratic quality. Here, it is the architecture of such large technical systems rather than single technical components that is pivotal. The architecture includes the way technical components are integrated into the system, how they inter-work, and how tightly they are linked to one another. These features can be more or less compatible with the values and structures of democracy. The architecture is based upon technical standards, and in many cases these standards are developed and adopted by standards development organizations. Thus, standardization provides an important institutional opportunity to incorporate social and political values in the design process.

A second peculiarity is linked to the network nature of ICT. A generic property of a network technology is the interdependence and 'complementarity' of the network's components and the positive and negative network externalities. Individual choices of designers and users have effects which are not restricted to the individual itself but also affect other current or (subsequent) potential designers and users. Potential users, in particular, may be attracted or excluded by these externalities. Once put into operation the technical specifications of the installed base are extremely difficult to change. The technology's basic structure determines its future developmental path (cf. Arthur 1989). It also shapes the expectations of potential users by requiring their conformance to the emerging industry standards. This may severely restrict the scope of choices available to those who were not involved in the early stages of designing and 
using the technology. All choices concerning its design and use can be assessed from the point of view of their democratic ramifications.

This points again to the standardization process since standard-setting plays a particularly crucial role in the design process for these technologies. As a consequence of the path dependent character of the development of network technology, standardization has moved towards the early stages of technological design. ICT standards do not simply endorse or rubber-stamp a wide-spread technological practice. They are rather adopted ex-ante in a bid to lock the development of a network into a predetermined pattern. Exactly this fact accounts for the significance of the process of standardizing ICT.

\section{Realizing democratic potential by design}

Before we look at standards development organizations and their institutional framework, it is necessary to develop an understanding of what the democratic potential of a technical system means. We already pointed out that there is no deterministic relationship between the design and architecture of a technical system and its repercussion on democracy. It cannot be asserted that some technical systems are intrinsically democratic and others are authoritarian as Mumford suggested with his distinction of these two types of technologies (Mumford 1967, 234242). However, more fine-grained distinctions that address the specific architectural and structural properties of technical systems in fact can aid in the assessment of their democratic potential. Winner, for instance, who emphasizes that a technical system "unavoidably" has a distinctive political effect, distinguishes between centralized or decentralized, egalitarian or inegalitarian, and repressive or liberating systems (Winner 1985, 31). He argues that solar energy, for example, as a disaggregated, decentralized technology, is "more compatible with a democratic, egalitarian society" than energy systems based on nuclear power (ibid, 32). Crucial to Winner is the distinction between flexible and inflexible technologies. While the design and architecture of flexible ones can be modified and changed during their development, there are no alternative designs available for inflexible technologies which would alter their political effects. Thus, in case of inflexible technologies, there remains only the initial choice to adopt or not to adopt (ibid, 36).

In terms of information and communication technology, the Internet has moved to the center of concern. It embodies the network of networks that interconnects a panoply of electronic devices and delivers a myriad of services, as foreseen by Ithiel de Sola Pool in his treatise on the "Technologies of Freedom" (Pool 1983). The Internet has certainly reinforced and re-inspired the discussion about the relationship between design and architecture of a technical system and democracy. If cyberspace is to be found right here in the real world (Shapiro 1999, 31), and if the architecture of standardized code (software) is akin to the "constitution" of cyberspace (Lessig $1999,5)$, then it is vital to make sure that this architecture is compatible with democracy. The following list of practical criteria which must be met by the architecture of a technical system is definitely not exhaustive but it includes central requirements which apply to the Internet and other ICT systems as well. We suggest that the design of an ICT system is democratic if it:

\footnotetext{
increases rather than reduces options of its use and its further development
} 
- is easy to access, easy to use and transparent (concerning transparency: "push technologies" such as "cookies" in the World Wide Web must be easy to detect, to block and to eliminate)

- is decentralized rather than centralized

- $\quad$ is unbundled (decomposable) rather than bundled (loosely rather than tightly coupled)

- $\quad$ is open (public) rather than proprietary (to avoid user lock-in)

- $\quad$ allows no usage control except for statistical and operational purposes (to optimize efficiency)

- facilitates encryption and other means to protect privacy.

Compliance with these criteria certainly does not guarantee that democracy will blossom nor that authoritarian control of citizens will be made impossible. Notwithstanding, a look at the history of the Internet and the correspondence of its technical architecture with a specific set of socio-technical values does suggest that architectural principles and cultural values have coevolved and reinforced each other (Diagram 1). Several architectural elements do appear to meet the criteria for democratic design and some of the values clearly do match the principles and rules of democracy. However, it must be conceded that the culture which prevailed at the earlier stages of development - in which the creators of the Internet were simultaneously its early users - is gradually changing. Current Internet users do not directly influence technology because they do not interact with the network but only use application software (cf. Castells 2001). This, on the other hand, leaves the central architectural and cultural principles of the Internet unaffected. Even if some developments of the Internet are observed with concern the fact that the network offers "extraordinary potential for the expression of citizen rights and for the communication of human values" leads to the conclusion that "it does contribute to democratization” (Castells 2001, 164).

\section{Diagram 1: Correspondence of Internet architecture and socio-political values}

\begin{tabular}{|l|l|}
\hline Elements of the technical architecture & Corresponding social values \\
\hline Decentralized network structures & Individualism, freedom, self-responsibility \\
\hline Minimal central coordination & $\begin{array}{l}\text { Mistrust towards bureaucracies and } \\
\text { hierarchies }\end{array}$ \\
\hline $\begin{array}{l}\text { Technical autonomy of networks, soft } \\
\text { integration }\end{array}$ & Respect for autonomy and heterogeneity \\
\hline $\begin{array}{l}\text { Open source software, public domain } \\
\text { software }\end{array}$ & $\begin{array}{l}\text { Creativity, cooperation, } \\
\text { participation }\end{array}$ \\
\hline Great variety of technical options & Innovativeness \\
\hline
\end{tabular}

(Source: Werle, 2002) 
The early development of the Internet was not coordinated through market processes. Different government agencies, research organizations and individual academics were involved in designing and standardizing the network. Pure market processes would appear to be ill-suited for providing for the democratic design of ICT. First, markets are not readily equipped to make allowances for the criteria discussed above; price signals alone do not guide the producers and users of technology towards democratic design; and markets only exert pressures towards efficiency, they cannot accommodate externalities. Second, because of the free-rider problem, price-market institutions generally fail to sustain socially desirable activities or to stop undesirable activities (Bator 1958). Consider for example ICT services and equipment designed to improve access for the handicapped or other underprivileged minorities. They usually lack the resources which would guarantee the provision of appropriate services and equipment. That means that in order to promote democratic design, non-market mechanisms must be activated and some public policy intervention in the form of regulation may be necessary. Standard setting via committees is one such mechanism which allows democratic design criteria to be considered during technological development.

\section{Standards development organizations and the design of institutions}

The design process of ICT involves choice and social negotiations. The systemic nature of this technology, which is comprised of components and involves linking groups of components, entails that negotiations take place and that decisions are made in the face of network externalities. Deliberations concerning the architecture of a technical system and the interoperation of the components often relate to standards which specify the components' interfaces (including the important system-user interface). Some decisions on standards are made in company labs, away from direct public influence. The emerging standards are only obligatory to the respective company, but they may diffuse via market processes and turn into de-facto standards which have never been formally adopted or endorsed by any industrial or political decision body. Often their emergence is not easy to trace. These standards are extremely difficult to change because they are incorporated in products owned and used by producers and consumers who want to avoid the costs of switching to another standard. Other standards are adopted in the more open and transparent context of standards development organizations (SDOs). Here committees of experts develop and decide on these technical specifications. Their work is governed by dedicated rules and principles which embody a significant part of the institutional design of the SDOs (cf. Goodin (ed.) 1996).

The rules that govern how different SDOs work can have far-reaching consequences. Committee-based standardization processes give rise to important questions of governance that have largely been overlooked (Abbott \& Snidal, 2001). In general, the question of how and under which institutional conditions decisions are taken in SDOs, has the scope to have consequences well beyond the bounds of the organization. Mattli (2001) emphasizes that standardization has the ability to influence industry-wide conduct, for example by moving competition away from product differentiation and towards marketing and distribution, where it influences industrial structures and sets the performance criteria for industries. 
But SDOs also have the scope to influence the democratic design of technical systems. They can open up opportunity structures for the systems' democratic design while identifying and addressing risk factors that may threaten democratic quality. The technical choices made "by committee" impinge on other choices, including those made by agents on the market. Some institutional rules of SDOs differ from organization to organization while others are shared. The rules shape the processes of collaboration, negotiation, consensus building and decision-making and they can be assessed from the angle of democracy. If we assume that the compatibility of technical architectures with principles of democracy is contingent on the democratic quality of the design process, the institutional arrangement of standardization processes gains crucial importance.

\section{Proliferation of committee standardization}

The potential of SDOs to influence the democratic design of information and communication technology is based upon the unique position these organizations have acquired over time. Even though many standards have evolved in the market as de-facto standards, the SDOs have played a key-role in the development ICT. ${ }^{\text {iii }}$ In a sense, communications and information technologies have to a large degree grown up and begun to converge beneath a forest of alphanumeric acronyms like x.400, x.25, and more recently ISO/IEC 8802.3 CSMA/CD, GSM, RFC821, http, html etc. The bases for central information and communication technologies for cell-phones, fax-machines, local-area networks, transmission protocols and many others, have been elaborated in and recommended by an alphabetic grove of international and regional standards development organizations such as ETSI, ANSI, ISO, ITU-T or IEEE, or in the thriving undergrowth of standards consortia such as the ATM forum, OMG, IETF or W3C.

Technological convergence and the general internationalization of markets account for the apparent increase in importance of SDOs at the regional and international level. The changes of the landscape of standardization organizations can be described in terms of several dimensions:

- There is a proliferation in number and type of standardization organizations. The increasing number of SDOs suggests that there is more room for relevant actors to participate in meaningful ways. It also means that only very few actors can participate at all layers, not least because of the expense of cumulative membership fees.

- The landscape of SDOs is characterized by an increasing degree of competition in the "market for published standards" (David, 1995) but also an increasing degree of coordination and cooperation between different, more "official” SDOs and more "informal” consortia via liaison arrangements (Werle, 2001a).

- Differences between "official” and "informal” SDOs tend to be exaggerated (Egyedi, 2001). Often standards are the results of a "hybrid selection process" combining market mechanisms and committee negotiations (Vercoulen \& van Wegberg, 1999).

- $\quad$ A general trend prevailing in ICT is the shift towards anticipatory standards or early standardization where the standardization process resembles a product development activity. If users have access to anticipatory standardization they can play an active role in the process and influence the design of technology (Foray, 1995). - The headline-trend in committee standardization can be summarized as a move from regulation to coordination, from national to regional and international standardization, from intergovernmental and other official organizations to private consortia of standardization, from ex-post to ex-ante (early) standardization and from a predominantly technical to a business approach (Werle, 2001b) 
These elements of the changing landscape of SDOs indicate that new institutional forms of standardization have emerged whose democratic quality should be assessed. But also traditional SDOs have never been systematically evaluated with regard to the respective criteria.

\section{Organizations and rules of standardization and their democratic quality}

The rules and procedures of committee-based standardization provide the institutional framework in which technical choices are arrived at by diverse sets of interests. Generally the decision-making process will involve a range of human actors who represent a variety of market but also non-market interests, including (but not limited to) regulatory, academic and military representatives. The actors are either individual members of the SDO or they are agents of an organizational member. The rules and procedures serve to shape the way diverse interests interact in defining technical characteristics of systems. The choices reflect the competencies, as well as views, concerns, and values present in the committee's process of exchange and negotiation. These then have the scope to become embedded in the design of the technologies, potentially yielding attributes that can become locked-in by strong complementarities in ways that are quasi-irreversible (cf. David \& Werle 2000).

A closer look at the global landscape of standardization organizations in ICT would indicates that they are heterogeneous in terms of several dimensions. But we would also find similarity concerning crucial institutional features (Werle 2001b).

- Participation in SDOs is within certain membership rules open to those who are "substantially interested."

- The work is committee-based, cooperative and consensus-oriented. It follows formalized rules and procedures.

• $\quad$ Working procedures are impartial and politically independent (“due process”).

- $\quad$ SDOs are non-profit organizations.

- The adopted standards are non-mandatory and public goods. They are not always free of charge but fees are charged on equal terms

All these features conform perfectly to the basic principles of democracy but they do not guarantee a democratic standardization process. Openness, for instance, does not assure that every interested actor in fact has access to standardization. In most SDOs, participation is not remunerated and it is a rather expensive undertaking to contribute time and work to preparatory work while incurring membership fees and travel expenses. Moreover, many standards are highly technical and arcane and have little impact in terms of the democratic design of a technical system.

In order to tackle the issues in question more systematically we suggest distinguishing between input and output aspects of democratic standardization. In more general theoretical terms of democratic theory, the input orientation is associated with the idea of "government by the people" while the output orientation relates to the idea of "government for the people" (Scharpf 1999, 6ff). Direct participation and consensus are the central pillars on which input legitimacy rests. But usually they only work if local problems are addressed and all affected individuals have the opportunity to get involved in the decision-making process. With larger entities, it is often difficult to ensure adequate representation of those who cannot directly participate - a problem that also touches upon the democratic accountability of the decisionmakers. The consensus principle is problematic, too. It affords veto power to every individual 
involved and therefore appears to be practicable only in win-win situations of pure coordination or if a single technically optimal solution of a problem is available. Otherwise majority voting will be the only feasible decision-rule which, however, entails problems with respect to the protection of minorities.

Output legitimacy is generally derived from an institutional system's “capacity to solve problems requiring collective solutions" where a common interest in arriving at such solutions prevails (Scharpf 1999, 13). It requires that all interests be considered in the definition of the collective interest and that the process be governed by norms of fairness and equity concerning the distribution of costs and benefits. Procedural provisions are to avoid 'problem-overload' by assuring that only a narrow range of problems be dealt with. Whenever possible the potential impact of choices is to be assessed. Thus, from the output perspective, what is aimed at can be called "good governance" - to use a term which has been coined with a view at the European Union's "comitology" - and the adoption of regulations by the committee system through a “deliberative” process in which "technical” expertise plays an important role (Joerges, 1999). Concerning interest representation, the emphasis is not on proportionality but on inclusiveness. Institutional provisions are to provide a level playing field and to assure that the plurality of interests articulated by firms, interest groups, public-interest organizations and governments as well as private individuals be included in the deliberations. At the same time an 'interestoverload' has to be avoided because it would put the viability of decision-making in jeopardy.

\section{Rules affecting input legitimacy}

Standards development organizations blend input and output criteria in their institutional design and in their operations. The most important official international or regional SDOs such as the ITU-T, the standardization branch of the International Telecommunication Union (ITU), the International Organization for Standardization (ISO) or the European Committee for Standardization (CEN) and the European Telecommunications Standards Institute (ETSI) follow the principle of territorial representation in different ways. They adhere to the one-nation, onevote or a nation-based weighted voting decision rule, both of which allow in principle for majority voting. But at the working level — in the working groups and study groups of the SDOs where every participant has a (sometimes weighted) vote-consensus is aimed at. At this level, the work is done by experts from firms and other organizations which are direct members of the SDOs and not only part of national delegations. Thus, at the working level, the principle of national representation is complemented by the principle of 'functional representation'. Not only firms but also research organizations, government agencies, consumer associations and other groups and organizations are involved in developing standards. In no other type of SDO is input legitimacy as much appreciated as in the official international and regional SDOs. But the significance of the question of who is involved in and who is excluded from standardization is low only if it is confined to the aspect of territorial representation through national delegations. If inclusiveness is assessed from the vantage point of interest pluralism, representation is far from encompassing.

As indicated earlier, the prohibitive costs incurred by those being involved in these SDOs in effect act to exclude interested parties from participating in standardization. Thus, severe 
deficiencies are engrained in the established official SDOs themselves already at this basic level. Taschner (1999) indicate that there are three factors that tend to undermine balanced participation even where it is otherwise (morally) encouraged. These factors are the scarcity of financial resources to subsidize the participation of public interest groups, the danger that economic interests can stifle the voice of such groups, and voting rules that allow this voice to be circumvented (Taschner 1999, 1-2). Such factors pose barriers to the objective of providing for the participation by all social groups representing different interests and values in the standardization process. As such, these standards development organizations fall short of providing democratic (input) legitimacy at the interface of society and technology.

But also the informal standardization organizations have problems here. To most consortia, the question of territorial representation is virtually irrelevant. Even organizations such as the European Computer Manufacturers Association (ECMA) which initially restricted membership to firms engaged in Europe - in order to strengthen the firms' competitive edge and not to increase its own legitimacy - was opened to global players and non-European firms after a short period of time. Now the consortium calls itself the International Europe-Based Association for Standardizing Information and Communication Systems (Werle 2001a). While territorial representation is irrelevant to informal SDOs the consensus principle is a ubiquitous feature of committee standardization shared by official SDOs and consortia. Even though consensus is not the same as unanimity and practices have evolved to arrive at consensus in many official and informal SDOs, a tension between legitimacy and efficiency —if not a trade-off - in terms of adopting many standards quickly is undisputable (Hawkins, 1995a; Rada 2000). ${ }^{\mathrm{v}}$ The problem becomes more aggravated the more diverse the interests involved in a standards committee are. This is one reason why several consortia target industrial parties but hesitate to involve other stakeholders and participants as they might increase diversity. But also in this respect the difference between official and informal SDOs is one of degree rather than of principle (cf. Egyedi, 2001).

\section{Rules affecting output legitimacy}

The issue of inclusiveness of SDOs concerns the pluralism and diversity of interests that are involved in standards committees, and it relates to input as well as to output aspects of legitimacy. While the input view stresses that these interests be proportionally included to their relative weight in the population of a given territory, the output perspective places more weight on facilitating access to SDOs and on involving as many diverse interests as necessary to assure that the public interest is appropriately considered and a democratic design of technology emerges. What counts at the end of the day is that the design of a technical system provides for compatibility with established principles of democracy no matter how the details of the design process are shaped.

It has been argued that the Internet Engineering Task Force (IETF) is the most open and inclusive SDO in this respect (Froomkin 2003). Internet standardization has established itself completely detached from the official and informal SDOs. Standards are developed in one of numerous working groups of the IETF. These groups can be easily created, and many are wound up after they have finished their task. Participation in the working groups is open to anyone and a broad and unrestricted discussion of proposals via electronic mailing lists is possible. Only 
individuals (and not firms or other organizations) can be members of the IETF and all the work is done by volunteers. But the expectation that these features attract individuals with all kinds of interests and concerns to participate in standardizations is obviously misleading. Users, for example, "are as under-represented on the distribution lists and at the meetings [of the IETF] as they are on ITU-T and OSI committees" (Jakobs 2000, 157). "By and large, vendors, service providers, and to a lesser extent, academia dominate the lists and the meetings" (ibid).

This result is surprising but it only mirrors more recent developments. Originally the process of Internet development was open to many engineers, computer scientists and other academics. In a sense this group of pioneers was an exclusive circle, but they were at the same time developers and users of the network. Participation was not restricted to standard-setting which could not clearly be separated from other activities of network building. This was an ideal situation to produce democratic output, i.e. a technical structure which matches and reinforces the cultural and political values of a societal group which was committed to the principles of pluralism, participation and transparency (cf. David and Werle 2000; also CSTB 2001, 23-45).

The user of the grown-up, technically sophisticated Internet and other mature information and communication technology, can be more adequately designated as a consumer who lacks the technical expertise to come up with meaningful concepts and specifications which express his or her needs and preferences. But this does not mean that lay consumers do not have needs and preferences or that they do not deserve to be considered in the process of technical development. Rather, the question is how these consumers and other lay groups and/or their needs and preferences can be substantially involved in standardization as a relatively transparent stage in the development of a technical system.

\section{Towards output legitimacy?}

The distinction between input and output legitimacy is helpful in assessing current changes of the landscape of standardization organizations. For instance, emphasizing inputlegitimacy along the lines sketched above would entail participation requirements which are unsuitable to the growing number of informal organizations, especially those established at the international or the regional level. Even though these organizations are open to government officials, they do not grant them privileged status, and the officials do not claim to be representatives of a certain country or territory. As long as the standards being adopted by informal or official SDOs are voluntary and not promulgated as regulations, input legitimacy is of minor importance. But voluntary standards also entail "public interest" aspects, and occasionally voluntary standardization intersects with regulatory processes. Moreover, the fact that in network industries such as ICT standards tend to lock-in and then exert a soft implementation pressure on those who would prefer another standard indicates a need to be legitimated as well (cf. Hawkins 1999).

Early on, SDOs were aware of these problems and they have been trying to cope with them by strengthening output legitimacy. Their initial response was to stimulate user participation. But the users involved were big companies from industries such as media, finance, aerospace or defense, and only later efforts were extended to promote broader consumer involvement in standardization. Since the early 1990s consumers have been represented in the 
majority of larger informal and practically in all official SDOs in the industrialized world (Schepel and Falke 2000, 101ff). In many countries consumer representation is financially supported by governments, usually at the national level. Whether or not consumer participation at this level has an effect on international standardization depends on the role national standardization organizations can play in the international context. ${ }^{\mathrm{ii}}$ In Europe, where the European Commission has traditionally been involved in mandating standards and shaping the institutional landscape of standardization (Werle and Fuchs 1993), steps have more recently been made to approach the question from another angle, for example by contributing funding to the European Association for the Co-ordination of Consumer Representation in Standardisation (ANEC). ANEC is based on a network of more than 200 consumer representatives across Europe, and it points to the aspect of legitimacy involved. It claims that "proper consumer participation at all levels is vital for the credibility of the system" but ANEC stresses at the same time that "the lack of resources [is] the main obstacle to stronger consumer participation in standardization." "iii Promotion of consumer participation in standardization is based on the assumption that recognizing consumer requirements improves the quality of standards. The requirements are to be brought to bear by experts from different areas of technological expertise. If successful, consumer participation works to promote standards that are good from the consumer perspective, and this provides output legitimacy.

The basic rationale for consumer participation can be generalized: the social utility of technical systems can be maximized by involving all concerned parties (stakeholders) and taking into account as many interests as possible at an early stage of the design process. The stakeholder approach which is instrumental in providing output legitimacy is processed in different variants in terms of the involvement of various groups of stakeholders and the directness of their participation. But we also find other approaches to ensure that non-industry or public policy and democracy interests are considered in standardization.

\section{Addressing democratic design via output legitimacy of ICT standardization}

One key aspect of using the standardization process to address the democratic design of ICT systems then concerns the effective integration of a greater plurality of interests into the standardization process. A sufficiently broad representation of interests is generally seen as in the best interest of the standardization process, even if it comes at the cost of the process taking longer. Broader involvement among vendor and user groups can help insure that the output reflects the needs and preferences of the market. The involvement of these groups is linked to the efficiency of the standardization process. It is obviously inefficient to arrive at a standard technology nobody wants, no matter how quickly it was arrived at. But from the point of view of designing technology which is compatible with the principles of democracy, participation cannot be restricted to producer and consumer involvement. Broadening the basis of output legitimacy requires the participation of other stakeholders representing non-market interests such as trade unions and environmental groups.

\section{Limits of the stakeholder approach}


In Europe in particular, trade unions participate in some areas of standardization. They mainly focus on health and safety standards which are often mandated by the European Commission and have the character of binding regulations rather than voluntary standards. In 1989, the European Trade Union Confederation (ETUC) set up a Technical Bureau for Health and Safety (TUTB) which became an associated member of the European Committee for Standardization (CEN) in 1993. ${ }^{\text {iiii }}$ Similar developments can be observed at the national level. In Germany, for instance, the Trade Union Federation (DGB) called for a "democratic" process of standards development as early as 1975 . "Despite some major progress", this demand is considered to be, "as much a live issue as ever" (Bamberg 2003, 6). It has been estimated that among some 26,000 experts involved in standards committees of the official German standardization organization (DIN), a mere one tenth of a percent represent employees (ibid, 5). Without financial support by the German government, representation would be even weaker. While in northern European countries experts from trade unions actively participate in the technical work of the standards committees, their participation in southern European countries is “all but non-existent” (Schepel and Falke 2000, 123).

Participation of environmental groups in standardization is "still in its infancy" - at the European as well as at the national level (ibid, p. 125). In 2000, the European Environmental Bureau (EEB), the Federation of Environmental Citizens Organizations, suspended its membership in the CEN's Strategic Advisory Body on Environment (SABE) because SABE was "not equipped to have a real impact" on standardization. ${ }^{\mathrm{xx}}$ Moreover, the European Commission continued to reject a proposal by the EEB to fund direct involvement of environmental groups in the standardization process. But the newly founded European Environmental Citizens Organisations for Standardisation (ECOS) were awarded an EU contract, starting on November 1, 2002, which facilitates the coordination of input of environmental organizations into standards work and representation of the members of ECOS at the EU institutions and European Standards Organizations. Assisted by the EEB, ECOS will send experts to technical committees and working groups. ${ }^{\mathrm{x}}$ The German DIN arranged for consideration of environmental aspects in the national standardization process through setting up a coordination office for environmental protection. This office, funded by the government, examines standards at the draft stage with respect to environmental issues. Furthermore, a contractual agreement with the government obliges the DIN "to work towards strengthening the weight of environmental concerns in European and international standardization” (Schepel and Falke, 2000, 126).

The German corporatist tradition which is favorable to private interest- government arrangements has triggered far-reaching procedural provisions to involve in standardization consumer, employee and environmental groups (Voelzkow 1996). But even in this country a participation deficit of these groups could not be avoided (ibid, 230ff).

Different formats have been chosen throughout Europe to facilitate participation of consumer, employee, and environmental groups in standardization. ${ }^{\text {ii }}$ In some instances, group representatives have direct access to the committees in which the detailed standardization work is done. In other cases special committees have been set up in the SDOs to monitor the standardization work and to provide input into the working committee process if and when it appears necessary. Again in other cases, experts from consumer, employee or environmental 
groups are members of the boards of standardization organizations where they have the opportunity to draw attention to the interests they represent but cannot feed them directly into the standardization work. Consumer groups and, to a greater degree, the other groups stress the lack of funds and other resources as being the main obstacle to effective participation in standardization (cf. Schepel and Falke 2000, 111-127). But, as has been argued concerning user participation in standardization, "the resource problem is actually a symbol of a number of more basic problems" (Hawkins 1995b, 28). These include the problem that single individuals who are delegated by a consumer, environmental or employee group into a standardization committee usually have a narrow focus of expertise which does not cover all aspects of a standard and in particular its cross references to other standards being developed in other committees. More serious is the issue of appropriate representation of the groups' interests. Often it is difficult to establish that the view presented by the expert who represents a group is in fact the collective view (cf. ibid).

No matter how they are initiated - either within the standards development organizations or by government encouragement or insistence - policies designed to widen the involvement of interests in the standardization process face fundamental problems. We have illustrated some of them. The voluntary nature of standardization, the openness of SDOs to all kinds of "interested" actors, the rules of due process and the consensus principle suggest that the institutional prerequisites exist to assure the adoption of good standards, i.e. technical standards which come close to the expectations and values of the actors involved. Official and informal SDOs share these prerequisites, but they cannot rule out the risk of indivdiual business firms controlling the standardization process at the international, the regional and to a minor degree also at the national level (Salter, 1999). Without public funding and other support, non-industry interests would not be represented in the standardization process at all. But direct involvement of experts from consumer, employees and environmental groups in the SDOs often fails to meet the expectations these groups associate with it. There is little evidence that their interests are often considered seriously in the standardization process. Thus, one can have doubts that "further efforts" to increase the participation of interested circles and to "pro-actively support participation of relevant stakeholders in standardisation work at the national, European, and international levels" will really have the effect intended by the European Commission. ${ }^{\text {iii }}$

Taken seriously, the stakeholder approach must also provide for the participation of civil liberties organizations and public interest groups in the standardization process. More than consumer, employee or environmental groups these organizations struggle for technical solutions which secure openness, help protect privacy and provide other elements of a democratic design of ICT systems. Adding public interests groups to the circle of actors actively involved in standardization, increases heterogeneity which is appreciated from a democratic design perspective but is problematic in terms of the efficiency and timeliness of standards adoption. 'Complexity overload' at the working level of standards development will not only slow down the process but - given the consensus and due process principle - it often will result in an impasse or non-decision. In voluntary standardization "forum shopping", i.e. switching from an overloaded SDO to one which is more exclusive or setting up a new private consortium with initial membership only from industry — would be one way out of this dilemma (Werle 2001a). 
This option is available to big firms and "technology leaders" who may even chose to push their standards into the market without involving a standards committee (Austin and Milner 2001). Such bypass strategies apparently run counter the intention of providing the institutional conditions for the democratic design of technology. They reveal the limits of the stakeholder approach.

\section{Broadening the cognitive and normative frame of standard-setting}

If the legitimacy and democratic quality of standards adopted in SDOs is assessed using output rather than input criteria, then the aspect of direct participation of diverse interests in the standardization process loses significance. But it remains important to make sure that non-market interests and values be attracted and integrated into the process. Thus, as an alternative-or an addition — to launching a more active policy to involve non-market actors directly in the standardization process, attention should be paid to ancillary measures which help ensuring that non-market aspects are considered and awareness is directed to the democratic design of technology.

For a long time, the cognitive frame of the standards developing process was a technical one. Standardization was perceived as a search process aiming at finding the technically optimal solution which then was easy to agree upon. The technical discourse prevailed and non-technical arguments tended to be considered illegitimate (Schmidt and Werle 1993). Since the 1970s, the technical discourse has increasingly been supplemented and sometimes marginalized by a business oriented commercial discourse. ${ }^{\text {iiii }}$ Competitive concerns and profit interests are generally regarded as legitimate if not vital by the actors participating in standardization. Conflicting business interests are tamed only by the common interest in a standard and the resulting need to reach a consensus (Schmidt and Werle 1998). It must be seen on this backdrop that SDOs developed rules - often laid down in their bylaws - that addresses the role of intellectual property rights (IPRs), particularly patents and copyrights can play under what conditions in the standardization process (Iversen 2001). These rules have qualitatively changed during the past decade as the risks that the standardization process confronts essential IPRs have increased both in scope and in scale. (Iversen 1999). They aim at leveling the playing field, at preventing IPR holders from monopolizing the commercial benefits of a standard, but also at reiterating the public good nature of committee standards.

The IPR example demonstrates that it is possible - in this case by changing the rules of the SDOs - to modify the cognitive and normative frame which guides the standardization process. While in this specific case the rules are intended to influence the commercial discourse, other instances show that they can also serve drawing attention to non-technical and noncommercial issues. One example involves provisions which aim at integrating the specific needs of handicapped people in the standardization process. In many cases, ICT holds a unique promise for those with handicaps to gain access to services and, moreover, to important parts of the social life. Traditional design of ICT is not user-friendly in this respect and in effect excludes the social minority of the handicapped. Moreover, the group of the handicapped and their needs are very heterogeneous, because this category spans a wide range of individuals from those with impaired vision, to those with different types of other functional disabilities. Apart from practical 
difficulties in some cases, this heterogeneity is an additional obstacle to involving them into standardization processes directly.

Catering to the needs of the disabled is therefore one situation that calls for a more active public role. Public programs can help explore ways to enhance user-influence in the interest of improving the accessibility of the disabled to ICT. Public policies can also support relevant R\&D and influence companies but also relevant international forums to integrate the needs of the disabled in the design of digital technology. Norway, to give an example, has launched the "Information Technology for the Disabled (IT Funk)" program as a long term attempt to influence the development of standards and new legislation at the European level in order to improve the conditions for the disabled in the Information Society, in terms of accessibility to ICT systems and services (see Diagram 2).

\section{Diagram 2: Information Technology for the Disabled (Norway)}

A 4-year R\&D program (1998-2002) related to information technology for the disabled (IT FUNK), funded by the Norwegian Research Council, other government actors and industry.

IT FUNK is charged with the following tasks:

1) Support development and dissemination of universal design and other methodologies and instruments relevant for R\&D, which make ICT products and services more accessible and useful for all, regardless of disability.

2) Support R\&D aimed at ICT-based solutions which are important for the ability of disabled people to participate fully in society. Financial support is given to projects based on universal design-principles and to projects on assistive technologies such as speech and language technologies.

3) Challenge and support the ICT industry to improve the accessibility of their regular products and services, and develop solutions for persons with special needs.

4) Require the use of standards and guidelines for accessibility to ICT-based products and services in all projects funded by the Norwegian Research Council and other public bodies.

(Source: <www.itfunk.org/docs/engpres.html>)

Several times the Norwegian program refers to the "design for all” principles. They are included in the "Guidelines for standard developers to address the needs of older persons and persons with disabilities" mandated by the EU and the EFTA and adopted by the official European SDOs in 2002. ${ }^{\mathrm{vvv}}$ The guidelines are intended to raise awareness of these issues and principles and to encourage standards committees to address them in their work. They also give instructions how to proceed when considering technical solutions and its alternatives. But they do not require the group whose needs are considered to be present in the standardization process.

Recently ANEC published a long catalogue of "Consumer Requirements in Standardisation relating to the Information Society” meant as "a guidance document addressed to 
standards-makers” (ANEC 2003, 3). Based on a comprehensive understanding of the consumers' needs and with a main focus on the Internet, ANEC recommendations come close to some of the principles of democratic design outlined above. These guidelines, too, are meant to influence the cognitive and normative frame of standardization in SDOs (cf. Hawkins 1995b, 35ff). They usually do not require direct participation in committees but would not preclude it either.

The Internet has stimulated a broad debate regarding the democratic quality of the standardization process focusing on IETF and the World Wide Web Consortium (W3C) (Froomkin 2003, Russell 2003). More than in other contexts of standardization, general aspects of the democratic design of the network rather than special consumer, employee or environmental interests are emphasized in this debate. But only a few public interests and civil society groups highlight the significance of standardization. Among them is the Center for Democracy and Technology (CDT) (http://www.cdt.org). This public-interest advocacy group has most actively promoted the democratic design goal in standardization. In 1996, the CDT convened the Internet Privacy Working Group which initiated the development of technical privacy specifications in the W3C. Some members of the working group were directly involved in the standardization work of the W3C. They participated in developing the Platform for Privacy Preferences (P3P) standard. This standardized technology communicates the privacy policies of web sites to the users that connect to them (Cranor 2002).

The experience gathered in this activity - but also in several cases in the IETF - has been analyzed by members of the CDT's Standards, Technology and Policy project (Davidson et al. 2002; Morris and Davidson 2003). They point to the limitations of direct participation of public interest advocates in standardization. Direct ongoing participation is regarded to be most effective, as in the case of P3P, but extremely time and resource intensive and, thus, not feasible as a standard operating procedure. But also the less resource-consuming ad hoc mode of participation is considered to be of limited usefulness because the public interest advocates remain in the role of an outsider whose suggestions can be easily dismissed by the committee. An alternative to direct participation is seen in monitoring and tracking the work of standards committees by the public interest community (Davidson, Morris and Courtney 2002). This requires the standardization process to be open and transparent.

This latter strategy has been taken up by the project members. They developed a tool which they call "ritualized public policy impact assessments" in the Internet standards development process (Morris and Davidson 2003, 1). In 2003, the CDT submitted a draft document to the IETF which aims at creating awareness of potential policy impacts of the IETF's design decisions. ${ }^{\mathrm{vV}}$ The document includes a list of more than 25 questions related to seven categories of public policy concern, ranging from "Content Censorship and Control” to "Personal Privacy." They shall be addressed by the standard developers when they design new technologies. Although this formal public policy impact assessment process has not been implemented in the IETF it is characteristic of the efforts to broaden the cognitive and normative frame of standardization in order to promote the democratic design of ICT.

\section{Conclusion and public policy implications}


The significance of information and communication technology for a democratic society is not contentious. It has been underpinned by the expectations linked to the proliferation of the Internet. The network of networks is regarded to facilitate electronic democracy and online democracy. Like other technologies ICT does not automatically strengthen democracy. Its effects are partly contingent on the purposes for which the technology is used. But the effects are also shaped by the design and architecture of ICT. The design can be more or less compatible with the general principles of democratic governance which include openness, equality, access, transparency, and accountability.

ICT systems which are decentralized and decomposable, open, transparent and easy to access and use, and which allow no usage control and protect privacy are more compatible with democracy than systems which lack all or some of these properties. In the process of ICT development these aspects are usually not systematically considered. Technical and economic factors have priority while compatibility with democratic principles is, if at all, of minor importance. Thus, whether or not a technology supports or impedes democracy can rarely be directly attributed to the interests and preferences that shape the design process. The democratic quality results rather from historical accident. The seminal example is the evolution of the Internet and of the TCP/IP protocols on which the network is based. No master plan existed which guided the development of the Internet. While the democratic dividend of the public domain nature of TCP/IP is undeniable, investments into this protocol have not been made with the intention to earn such a dividend.

This does not mean that the architecture and function of technology cannot be designed in a way that supports or is at least compatible with democracy. But the opportunities for public policy to influence the design process are limited. Usually technical research and development takes places in company labs hidden from the public and from potential competitors. Companies which have invested into new technologies legitimately strive for a competitive advantage to recoup the investment and therefore are compelled to protect it from free-riders. The development of common technical standards is one of the rare occasions in which companies partly disclose their innovations. They do so voluntarily because they expect to benefit from the agreement of a common standard. Complex technologies are coordinated via standards. The coordination needs have increased considerably in the innovative area of ICT, and practically in parallel the number of standards committees in official SDOs as well as private consortia has grown. Standards determine the future development of an ICT system to a certain degree. If they are adopted in an early developmental stage they can have long lasting effects. The relative transparency of the committee process and the significance of standards for the structure and further development of ICT systems make standardization attractive for public policy intervention.

The institutional structure of the majority of SDOs at the national, regional and international level shows a high degree of similarity. Formally, participation is open to all "substantially interested" actors. The working procedures follow due-process principles and are consensus-oriented. SDOs are non-profit organizations and their standards are non-mandatory and public goods. These features conform to the principles of democracy, but as such they do not guarantee the democratic legitimacy of the input into or the output of the standardization process. 
Participation in standards development is time-consuming and resource-intensive. It is not remunerated by the SDOs. Developing standards also requires technical expertise. Taken together it is not surprising that the majority of participants in standardization are agents from firms or public research organizations. Given the plurality of interests and values in society these agents are definitely not representative. The bias towards industry interest representation is with few exceptions - strongest at the international level, where even small and medium-sized enterprises are absent.

Balancing interest and value representation through direct participation of all affected or interested groups appears to be illusionary. Apart from the considerably high costs, direct participation would likely result in complexity overload and deadlock in the committees. The overloaded SDOs would be bypassed and standardization would migrate into even more exclusive private consortia. Given the prevalence of technical and commercial argumentation in standardization only consumer representatives can be integrated in the standardization process relatively easily because they speak for the demand side of the market which cannot be ignored by firms. But even consumer representation has to rely on financial governmental support in most cases.

Consequently, efforts to facilitate consideration and involvement of the plurality of interests and values, including basic principles of democracy, in standardization have shifted from the input to the output side of the process. These efforts - assisted and funded by governments - vary with regard to their specific starting-point. But they share the goal stimulating participants in standards developing processes to consider potential non-market and non-technical impacts of standards. They aim at broadening the cognitive and normative frame of the standardization discourse and creating awareness of a standard's public policy implications. Direct participation of advocates of consumer, employee, environmental or more encompassing public interests can help directing awareness to issues which would have otherwise not been considered. But also issuing guidelines concerning the inclusion of nonmarket interests and democratic principles in the standardization process can be helpful, especially if they are included in the bylaws of an SDO. In other instances the work of standards committees is monitored and "reviewed" by special committees from outside or by special boards within the SDOs and an assessment is returned to the standards committees. The committees are expected but usually not obliged to consider the evaluations and recommendations and modify the standards. All these measures aim at creating "good standards.” If adopted and implemented these standards would provide the basis for the emergence of ICT systems which are compatible with the principles of democracy. It would, however, mean overestimating the significance of standards would one infer that solely standards determine the architecture and function of an ICT system and its democratic quality. 


\section{References}

Abbott, K. W. \& Snidal D. (2001). "International 'standards' and international governance". Journal of European Public Policy 8 (3), 345-370.

ANEC (2003). Consumer Requirements in Standardisation relating to the Information Society. Brussels: Association for the Co-ordination of Consumer Representation in Standardisation http://www.anec.org

Arthur, W. B. (1989). “Competing technologies, increasing returns and lock-in by historical events.” Economic Journal 99, 116-131.

Austin, M. T. \& Milner, H. V. (2001). “Strategies of European standardization”. Journal of

European Public Policy 8 (3), 411-431.

Bamberg, U. (2003). The role of German trade unions in the national and European standardization process. Brussels: European Trade Union Technical Bureau for Health and Safety (TUTB). <www.etuc.org/tutb/uk/pdf/TU-report-germany.pdf>.

Barber, B. R. (2002). "The Ambiguous Effects of Digital Technology on Democracy in a Globalizing World”. In: Banse, G., Grunwald, A. \& Rader, M. (Eds.), Innovations for an eSociety. Challenges for Technology Assessment. (pp.43-56). Berlin: edition sigma.

Bator, F. M. (1958). "The anatomy of market failure”. Quarterly Journal of Economics LXXII, 351-379.

Catinat, M. \& Vedel, T. (2000). "Public Policies for Digital Democracy”. In: Hacker K. L. \& Dijk J. v. (Eds.), Digital Democracy. Issues of Theory and Practice. (pp.184-208). London: Sage.

Castells, M. (2001). The Internet Galaxy. Reflections on the Internet, Business, and Society. Oxford: Oxford University Press.

Cranor, L. F. (2002). Web Privacy with P3P. Beijing/ Cambridge/ Farnham: O’Reilly.

CSTB (Computer Science and Telecommunications Board), National Research Council (2001). Global Networks and Local Values. A Comparative Look at Germany and the United States. Washington, DC: The National Academy Press.

David, P. A. (1995). "Standardization policies for network technologies: the flux between freedom and order revisited”. In: Hawkins, R., Mansell, R.\& Skea, J. (Eds.), Standards, innovation and competitiveness. (pp.15-35). Aldershot: Edward Elgar.

David, P. A. \& Werle, R. (2000). The Evolution of Global Networks: Technical, Organizational and Cultural Dimensions. Internal Background Paper for the CSTB Committee Report on "Global Networks and Local Values." Oxford, Stanford and Cologne: <www.mpi-fg-koeln.mpg.de/Internet/III.1_daakpdrw.htm>.

Davidson, A., Morris, J. \& Courtney, R. (2002). Strangers in a Strange Land: Public Interst Advocacy and Internet Standards. Washington, D.C.: Center for Democracy and Technology. $<$ www.cdt.org/publications/piais.pdf $>$

Egyedi, T. M. (2001). Beyond Consortia, Beyond Standardisation? New Case Material and Policy Threads. Delft, the Netherlands: Delft University of Technology. <europa.eu.int/comm/enterprise/standards_policy/study/consortia_standardisation.htm>

Engel, C. \& Keller, K. H. (Eds.) (2000). Governance of Global Networks in the Light of Differing Local Values. Baden-Baden: Nomos. 
Foray, D. (1995). "Coalitions and committees. How users get involved in information technology (IT) standardization". In: Hawkins, R., Mansell, R. \& Skea, J. (Eds.), Standards, innovation and competitiveness. (pp.192-212). Aldershot: Edward Elgar.

Froomkin, M. A. (2003). "Habermas@discourse.net: Toward a Critical Theory of Cyberspace". Harvard Law Review 116 (3), 749-873.

Genschel, P. (1997). "How Fragmentation Can Improve Co-ordination: Setting Standards in International Telecommunications". Organization Studies 18 (4), 603-622.

Goodin, R. (Ed.) (1996). The Theory of Institutional Design. Cambridge: Cambridge University Press.

Hawkins, R. (1995a). "Standards-making as technological diplomacy: assessing objectives and methodologies in standards institutions". In: Hawkins, R., Mansell, R.\& Skea, J. (Eds.), Standards, innovation and competitiveness. (pp.147-158). Aldershot: Edward Elgar.

Hawkins, R. (1995b). "Enhancing the User Role in the Development of Technical Standards for Telecommunications”. Technology Analysis \& Strategic Management 7 (1), 21-40.

Hawkins, R. (1999). "The rise of consortia in the information and communication technology industries: emerging implications for policy". Telecommunications Policy 23, 159-173.

Iversen, E. J. (1999) "Standardization and Intellectual Property Rights: Conflicts between innovation and diffusion in new telecommunications systems”. In Kai Jakobs (ed) Standards and Standardization: A Global Perspective. Idea Group Publishing (Pennsylvania, USA).

Iversen, E. J. (2001). "Patenting and voluntary standards: the tension between the domain of proprietary assets and that of "public goods" in the innovation of new network technologies". Science Studies 14 (2), 66-82.

Jakobs, K. (2000). Standardization Processes in IT: Impact, problems and benefits of user participation. Wiesbaden: Vieweg.

Joerges, C. (1999). ““Good Governance” Through Comitology”. In: Joerges, C. \& Vos, E. (Eds.), EU Committees: Social Regulation, Law and Politics. (pp.311-338). Oxford, Portland: Hart.

Lessig, L. (1999). Code and other Laws of Cyberspace. New-York: Basic Books.

Mackay, H. (1995). "Theorising the IT/Society Relationship". In: Heap, N., Thomas, R., Einon, G., Mason, R. \& Mackay, H. (Eds.), Information Technology and Society. (pp.41-53). London: Sage/Open University.

Mattli, W. (Ed.) (2001). "Governance and International Standard Setting". Journal of European Public Policy, Special Issue 18 (3).

Mattli, W. (2001). "The politics and economics of international institutional standards setting: an introduction". Journal of European Public Policy 18 (3), 328-344.

Mattli, W. (2003). "Public and Private Governance in Setting International Standards". In: Kahler, M. \& Lake, D. A. (Eds.), Governance in a Global Economy: Political Authority in Transition. (pp. 199-225). Princeton, Oxford: Princeton University Press.

Morris, J. \& Davidson, A. (2003). Policy Impact Assessments: Considering the Public Interest in Internet Standards Development. Washington, D.C.: Center for Democracy and Technology. $<$ www.cdt.org/publications/pia.pdf>

Mumford, L. (1967). The Myth of the Machine: I. Technics and Human Development. New York: Harcourt. 
OTA (Office of Technology Assessment) (1992). Global standards: Building Blocks for the future. Washington, DC: US Government Printing Office.

Pool, I. d. S. (1983). Technologies of Freedom. Cambridge, MA/ London: Belknap Press.

Rada, R. (2000). Consensus Versus Speed. In: Jakobs, K. (Ed.), Information Technology. Standards and Standardization: A Global Perspective. (pp. 19-34). Hershey, PA: Idea Group.

Rankine, L. J. (1995). Role of users in IT standardization. OECD STI Review: 16.

Russell, A. L. (2003). The W3C and its Patent Policy Controversy: A Case Study of Authority and Legitimacy in Internet Governance. Baltimore, M.D. <www.arussell.org/papers/alrtprc2003.pdf $>$.

Salter, L. (1999). “The Standards Regime for Communication and Information Technologies”. In: Cutler, A. C., Haufler, V. \& Porter, T. (Eds.), Private Authority and International Affairs. (pp. 97-127). Albany, N.Y.: State University of New York Press.

Scharpf, F. W. (1999). Governing in Europe: Effective and Democratic? Oxford: Oxford University Press.

Schepel, H. \& Falke, F. (2000). Legal aspects of standardization in the member States of the EC and EFTA. Volume 1, Comparative report. Luxembourg: Office for Official Publications of the European Communities.

Schmidt, S. K. \& Werle, R. (1993). Technical Controversy in International Standardization. Discussion Paper 5/93. Cologne: Max Planck Institute for the Study of Societies.

Schmidt, S. K. \& Werle, R. (1998). Coordinating Technology. Studies in the International Standardization of Telecommunications. Cambridge, MA: The MIT Press.

Sclove, Richard E. (1995). Democracy and Technology. New York, The Guilford Press.

Shapiro, A. L. (1999). The Control Revolution. How the Internet is Putting Individuals in Charge and Changing the World We Know. New York: PublicAffairs.

Tamarin, C. (1988). "Telecommunications technology applications and standards: a new role for the user". Telecommunications Policy 12, 323-331.

Taschner, Karola (1999). "Standardization's role in caring for society". Paper presented at the Standardization for the 21st century conference. <www.din.de/eustandconf/index.htm>. Vedel, T. (1999) “La gouvernance des réseaux mondiaux de communication”. Politique et Sociétés (18)2, 9-36.

Vercoulen, F. \& Wegberg, M. v. (1999). "Standard selection modes in dynamic, complex industries: Creating hybrids between market selection and negotiated selection of standards". SIIT Proceedings of the 1st IEEE Conference on Standardisation and Innovation in Information Technology SIIT '99. Aachen, Germany, September 15-17, 1999. Piscataway, NJ: IEEE, 1-11.

Voelzkow, H. (1996). Private Regierungen in der Techniksteuerung. Frankfurt am Main: Campus.

Vries, Henk J. de (1999). Standards for the Nation. Analysis of National Standardization Organizations. Boston, Dordrecht: Kluwer.

Werle, R. (2000). "The Impact of Information Networks on the Structure of Political Systems". In: Engel, Christoph, Kenneth H. Keller (Eds.), Understanding the Impact of Global Networks on Local Social, Political and Cultural Values. (pp.167-192). Baden-Baden: Nomos.

Werle, R. (2001a). "Institutional aspects of standardization - jurisdictional conflicts and the choice of standardization organizations”. Journal of European Public Policy 8 (3), 392- 410. 
Werle, R. (2001b). "Standards and Standards Organizations in the International Free Trade Regime". Knowledge, Technology \& Policy 14 (3), 127-140.

Werle, R. (2002). "Internet and Culture: The Dynamics of Interdependence”. In: Banse, G., Grunwald, A. \& Rader, M. (Eds.), Innovations for an e-Society. Challenges for Technology Assessment. (pp.243-259). Berlin: edition sigma.

Werle, R. \& Fuchs, G. (1993).” Liberalization and Integration. Pathways to a trans-European network in telecommunications”. Utilities Policy 3 (3), 187-200.

Winner, L. (1985). "Do Artifacts have Politics?". In: MacKenzie, D. \& Wajcman, J. (Eds.), The Social Shaping of Technology. (pp.26-38). Milton Keynes: Open University Press.

\section{Endnotes}

\footnotetext{
A Congressional Research Service. Voluntary industry standards in the US: an overview of their evaluation and significance for the Congress, Report to the subcommittee on science, research and development, 1974. Cited in OTA 1992, 3.

${ }^{A}$ On the degrees of fit between democratic frameworks and large technical systems, see Sclove (1995).

${ }^{\text {A }}$ If not explicitly mentioned otherwise, standardization and SDOs refer to the organizations and processes of adopting coordinative standards or industry standards which are voluntary, while regulatory standards or regulations are imposed directly or indirectly by governments or other political authorities (Holznagel \& Werle, this issue).

A New participants in the working groups of the Internet Engineering Task Force (IETF) read the following instructions: "The general rule on disputed topics is that the Working Group has to come to "rough consensus," meaning that a very large majority of those who care must agree. The exact method of determining rough consensus varies from Working Group to Working Group. The lack of voting has caused some very long delays for some proposals, but most IETF participants who have witnessed rough consensus after acrimonious debates feel that the delays often result in better protocols” (http://www.ietf.org/tao.html\#9.1).

A They do have some leverage in the official international standardization organizations such as ISO or CEN (cf. de Vries, 1999; also Mattli, 2003).

A http://www.anec.org/anec.asp?rd=53342\&ref=01-01\&lang=en

A See for details http://www.etuc.org/tutb/uk/technical-standards.html

A See http://www.eeb.org/activities/standartisation/main.htm

A Ibid. http://www.eeb.org/activities/standartisation/main.htm

A See also Jakobs who discusses six different modes to involve users into the standardization process (Jakobs, 2000, pp. 159-160).

${ }^{A}$ General guidelines for the cooperation between CEN, CENELEC AND ETSI and the European Commission and The European Free Trade Association 28 march 2003 (2003/c 91/04).

A The IETF's widely cited philosophy: "We reject kings, presidents, and voting; we believe in rough consensus and running code" entails the conviction that standardization is about finding "running" technical solutions.

A CEN/CENELEC Guide 6, January 2002 (see: http://portal.etsi.org/hf/cen-cenelec_guide6.asp)

A Public Policy Considerations for Internet Design Decisions (http://www.cdt.org/standards/draft-morris-policyconsiderations-00.pdf)
} 